\title{
New-Onset Tourette Syndrome following Human Growth Hormone Therapy
}

\author{
Hakan Doneray ${ }^{\mathrm{a}}$ Huseyin Tan ${ }^{\mathrm{b}}$ Zerrin Orbak $^{\mathrm{a}}$ \\ ${ }^{a}$ Division of Pediatric Endocrinology and ${ }^{b}$ Division of Pediatric Neurology, Department of Pediatrics, \\ School of Medicine, Atatürk University, Erzurum, Turkey
}

Dear Sir,

Tics are described as spontaneous, brief, quick, sudden, recurrent, repetitive, purposeless, and stereotyped movements or noises [1]. Tic disorders are classified as (1) transient tic disorder, (2) chronic motor or chronic vocal tic disorder and (3) Tourette syndrome (TS). Of these, TS is the most severe form presenting with both multiple motor and one or more vocal tics and usually starting in childhood [1].

The use of human growth hormone (hGH) in children and adolescents is generally safe. However, it may cause some side effects in a minority of cases [2, 3]. There is no record of tic disorders being associated with hGH therapy. In this paper, a patient with TS whose motor and vocal tics developed during hGH therapy is presented.

\section{Case Report}

A 10-year-old boy was admitted to our hospital with a history of short stature. The family history was unremarkable. His height SDS was -2.5 . His bone age was consistent with that of an 8-year-old. He was of normal appearance and the physical examination was also normal. The testes were prepubertal based on the Tanner growth chart. The height velocity was below the 25th percentile for his age. Laboratory studies such as complete blood count, serum glucose, electrolytes, renal and liver function tests, lipid profile, thyroid func- tion tests, and urine analysis were normal. There were no factors causing short stature such as chronic illness, primary bone disease or a dysmorphic syndrome. Maximal plasma GH response to standard stimulation tests with clonidine and insulin was $<10 \mathrm{ng} / \mathrm{ml}$. Magnetic resonance imaging (MRI) of hypophysis was normal. The patient was diagnosed as having idiopathic growth hormone deficiency (GHD) and recombinant hGH at $0.03 \mathrm{mg} / \mathrm{kg} /$ day was started. He was followed up at 3-monthly intervals. Two years later, the height velocity of the patient increased from $3 \mathrm{~cm} /$ year to $8 \mathrm{~cm} /$ year. Physical and neurological examinations including optic disc and retina were normal except for motor and vocal tics such as throat-clearing sounds, shoulder shrug, and facial grimace. A detailed history revealed that tics developed approximately 6 months after hGH therapy was started. Shoulder shrug and facial grimace started almost at the same time and became increasingly severe. Eight months later, throat-clearing sounds became apparent. Motor and vocal tics occurred nearly every day but they decreased markedly during sleep. At that time, the psychiatric evaluation was normal. Laboratory studies including complete blood count, serum glucose, electrolytes, renal and liver function tests, lipid profile, thyroid function tests, prolactin, ceruloplasmin, antistreptolysin $\mathrm{O}$ antibody, and urinary cop- per excretion of $24 \mathrm{~h}$ were within reference values. The throat culture showed normal bacterial flora. Cranial MRI was normal but single photon emission computed tomography (SPECT) demonstrated hypoperfusion of the left frontotemporal region. The patient was diagnosed as having TS; thus, hGH therapy was discontinued. Two months later, although throat-clearing sounds completely improved, the intensity of shoulder shrug and facial grimace diminished but did not disappear. Thereupon, risperidone, an antidopaminergic drug, was started at a dose of $0.25 \mathrm{mg}$ at bedtime and increased to $0.5 \mathrm{mg}$ the following week. In the 3rd month of this treatment, the tics completely disappeared.

\section{Discussion}

Our case was diagnosed as TS based on the criteria defined by American Psychiatric Association's Diagnostic and Statistical Manual of Mental Disorders [1]. The patient had two motor tics and one vocal tic, which occurred nearly every day for more than 1 uninterrupted year, and which developed before the age of 18 years. Furthermore, tics are not due to the direct effects of a known medication.

The cause of TS is uncertain. However, autoimmunity, genetics, neuroanatomy, and neurochemistry are known to play a role in the pathophysiology of TS $[1,4]$.

\section{KARGER}

Fax +41613061234 E-Mail karger@karger.ch www.karger.com
(C) 2007 S. Karger AG, Basel 0014-3022/07/0572-0116\$23.50/0

Accessible online at: www.karger.com/ene
Hakan Doneray, MD

Haci Salih Efendi Mah. Ebu Ishak Cad

TEMA Sitesi A Blok 4/15, Yenisehir

TR-25070 Erzurum (Turkey)

Tel. +90 44231500 12, Fax +90 44223613 01, E-Mail hdoneray@hotmail.com 
Tics might develop following a group A $\beta$-hemolytic streptococcal infection, and the infusion of sera into rats from patients with TS resulted in significant oral stereotypy scores, both of which suggest the presence of autoimmune mechanism in TS [5]. Because streptococcal autoantibodies, known as an autoimmune cause, are a potential risk factor for TS, they should be investigated in children who suddenly develop tics [6]. Our patient had a long period of motor and vocal tics, and laboratory studies for streptococcal infection were unremarkable.

The genetic contribution to TS is thought to be very strong [4]. The familial transmission of disease is established, but a genetic cause with linkage analysis has not been identified yet [4]. Our patient had a negative family history of motor and vocal tics.

Previous MRI studies have demonstrated reduced volumes and abnormal volumetric asymmetries of the caudate, putamen, globus pallidus, and frontal lobe in TS patients [1]. SPECT studies have also shown perfusion differences in the same areas [1]. Photon emission tomography investigations have revealed metabolic rate differences of limbic regions of the cortex and striatum, and cortical regions [1]. Although not all imaging studies have yielded definitive findings, they suggest that affected areas might be implicated in the pathophysiology of TS. In our patient, cranial MRI was normal but SPECT demonstrated hypoperfusion of the left frontotemporal region.

Tics are likely to occur due to dysregulation of neurotransmitters in the abovementioned brain areas. Some drugs such as dextroamphetamine, pemoline, and methylphenidate, known to increase CNS dopaminergic activity, exacerbate TS symptoms, whereas drugs such as haloperidol that decrease the action of dopamine improve TS symptoms [1]. Selective serotonin reuptake inhibitors successfully treat TS associated with an obsessive-compulsive disorder [1]. Selective $\alpha_{2}$ adrenergic receptor agonists, such as clonidine and guanfacine, are effective for a number of TS patients [1]. These findings suggest that dopamine, serotonin and norepinephrine may be implicated in pathophysiology of TS. Altered transmission of these neurotransmitters has been associated with behavioral disorders including anxiety, depression, suicide, aggression and addiction [7]. These disorders have also been reported in children with GHD. A study comparing 109 GHD children with matched controls reported that disorders such as aggressiveness, social withdrawal, somatic complaints, anxiety-depression, delinquent behavior, attention deficiency and thought difficulty were significantly high in GHD [8]. The same study also demonstrated that 72 patients who completed 3 years of GH therapy had a significant improvement in all symptoms. In addition, GHD in adults was associated with detrimental psychological effects such as somatic pain, irritability, depression and increased tiredness, which improve with hGH therapy $[9,10]$. These findings suggest that effects of hGH in CNS are biochemically modulated. Recently, studies performed on rainbow trout showed that peripherally administered hGH increased brain dopaminergic activity $[11,12]$.

Numerous clinical studies have shown that some drugs can lead to exacerbation of TS symptoms [13-15]. Although the mechanism of action is still being elucidated, it is stated that prolonged exposure to medications may alter receptor functioning as well as synthesis or release of neurotransmitters, which are implicated in the pathophysiology of TS. In our case, tics developed 6 months after hGH therapy was started, and hypoperfusion of the left frontotemporal region was the only pathophysiologic finding suggesting that the patient was susceptible to TS. The development of tics in our case was attributed to the dopaminergic activity of hGH based on TS because when hGH therapy was discontinued, the vocal tic disappeared and the intensity of motor tics was diminished; motor tics completely disappeared after risperidone, an antidopaminergic drug, was started. However, the literature does not reveal any tic disorder associated with hGH therapy, which may be due to the fact that other patients receiving hGH therapy have no pathophysiologic findings suggesting TS. In addition, because some tics were slight, they might have been overlooked.

In conclusion, patients receiving hGH therapy and having any pathophysiologic findings suggesting TS should be asked about the presence of tics at each visit.

\section{References}

1 Kuperman S: Tic disorders in the adolescent. Adolesc Med 2002;13:537-551.

2 Rosenfeld RG, Cohen P: Disorders of growth hormone/insulin-like growth factor secretion and action, in Sperling MA (ed): Pediatric Endocrinology, ed 2. Philadelphia, Saunders, 2002, pp 211-289.

3 Clayton PE, Cowell CT: Safety issues in children and adolescents during growth hormone therapy - a review. Growth Horm IGF Res 2000;10:306-317.

4 Pringsheim T, Davenport WJ, Lang A: Tics. Curr Opin Neurol 2003;16:523-527.

5 Swedo SE, Leonard HL, Garvey M, et al: Pediatric autoimmune neuropsychiatric disorders associated with streptococcal infections: clinical description of the first 50 cases. Am J Psychiatry 1998;155:264-271.

6 Church AJ, Dale RC, Lees AJ, et al: Tourette's syndrome: a cross-sectional study to examine the PANDAS hypothesis. J Neurol Neurosurg Psychiatry 2003;74:602-607.

7 Jayanthi LD, Ramamoorthy S: Regulation of monoamine transporters: influence of psychostimulants and therapeutic antidepressants. AAPS J 2005;7:E728-E738.

8 Stabler B, Siegel PT, Clopper RR, et al: Behavior change after growth hormone treatment of children with short stature. J Pediatr 1998;133:366-373.

9 McMillan CV, Bradley C, Gibney J, et al: Psychological effects of withdrawal of growth hormone therapy from adults with growth hormone deficiency. Clin Endocrinol (Oxf) 2003;59:467-475.

10 Mahajan T, Crown A, Checkley S, et al: Atypical depression in growth hormone deficient adults, and the beneficial effects of growth hormone treatment on depression and quality of life. Eur J Endocrinol 2004; 151:325-332.

11 Johansson V, Winberg S, Jonsson E, et al: Peripherally administered growth hormone increases brain dopaminergic activity and swimming in rainbow trout. Horm Behav 2004;46:436-443.

12 Jonsson E, Johansson V, Bjornsson BT, et al: Central nervous system actions of growth hormone on brain monoamine levels and behavior of juvenile rainbow trout. Horm Behav 2003;43:367-374.

13 Erenberg G, Cruse RP, Rothner AD: Gilles de la Tourette's syndrome: effects of stimulant drugs. Neurology 1985;35:1346-1348.

14 Dietl T, Kumpfel T, Hinze-Selch D, et al: Exacerbation of tics by prednisolone. Nervenarzt 1998;69:1111-1114.

15 Kessler AR: Clonidine treatment increases tics in patients with Tourette syndrome: case report. J Child Neurol 2001;16:380-381. 